\title{
A Sociomateriality Perspective of Sustainable E-HRM Implementation
}

\author{
Anna Bos-Nehles and Tanya Bondarouk \\ University of Twente \\ Faculty of Behavioural, Management and Social Sciences \\ Human Resource Management Department \\ P.O. Box 217 \\ 7500AE Enschede \\ The Netherlands \\ e-mail: a.c.nehles@utwente.nl
}

Acknowledgement: The authors are very grateful for the support of Hannah Methorst during this research project. 


\section{Introduction}

Information and communication technology (ICT) lays at the core of most contemporary work processes and has led to major transformations in the way HRM is practiced. Due to the ongoing digitization, new innovative HRM software systems and activities (applications) have been developed. Combining them with technological information and web-based technologies, these applications are known to us as electronic-HRM (e-HRM) (Strohmeier, 2012). Thus, by linking HRM with modern technologies, organizational rules, regulations and business strategies, companies hope to gain a competitive advantage through the implementation of e-HRM applications (Srivastava, 2010; Vashishth, 2014).

Based on Klein und Sorra (1996), we define implementation as the process of gaining targeted organizational members' appropriate and committed use of the e-HRM application. We view implementation as an ongoing multilevel phenomenon, since individuals, groups, organizational units and even the organization as a whole, have to interact with each other to perform e-HRM activities (Strohmeier, 2007). The implementation of e-HRM, however, does not always lead to expected results (Bondarouk \& Brewster, 2016a) since "there is often a discrepancy between the promised benefits and its realized outcome" (Parry \& Strohmeier, 2014, p. 125). Despite assumptions of a positive impact (Bondarouk et al., 2009a), if not implemented properly, success of e-HRM applications will be at risk.

Taking into account that e-HRM implementation is an ongoing multilevel phenomenon (Strohmeier, 2007) that links HRM, modern ICTs and organizational rules and regulations, various stakeholders are responsible for the implementation of sustainable e-HRM. Following existing definitions of sustainable HRM (Ehnert et al. 2015), we define it as applying ICT to support and network relevant actors in their shared performing of HRM that is directed towards simultaneously supporting the economic, ecological and social performance of an organization. 
There are different stakeholder groups that together are responsible for the implementation of sustainable e-HRM: HRM, technology and organizational stakeholders. We see a mutual continuous interaction between HRM, technology and organization, in which all three in some way affect or react to each other. Since traditional management literature has confined itself to studying only one part of the interplay between e-HRM applications, Orlikowski and Scott (2008) stress the essence of exploring and understanding the social, material forms and spaces, to find out how they are bound up with the organizational structure they are part of. The concept of 'sociomateriality' provides a theoretical framework to study social and material dimensions that influence the implementation of sustainable e-HRM applications (Orlikowski \& Scott, 2008). A sociomateriality perspective is recommended to study e-HRM phenomena in organizations, since it is considered as a "fruitful vehicle to analyze and understand the situated conditions of technology use" (Ellmer \& Reichel, 2017, p. 270). This perspective helps us to answer the central research question, being: In what way do social and material dimensions interact in the process of implementing e-HRM applications sustainably?

\section{A Sociomateriality Perspective}

To Leonardi (2013), sociomateriality is one of the most popular, most cited and most debated topics in the field of information systems and management. It is based on the premise that technologies have no inherent meanings, but "acquire their form and attributes only through their relations with others in practice" (Orlikowski, 2009, p. 12). In a sociomateriality perspective, there are no distinct and separate social or technological elements that shape, or be shaped by, each other. Instead, technology should be treated symmetrically to humans, and thus can be regarded as equivalent participants in a network of humans and non-humans that support each other (Orlikowski, 2009). This means that the social/human and material 
dimensions of the organization are inherently inseparable, as materiality is intrinsic to everyday activities and relations (Orlikowski \& Scott, 2008). Translated to the organizational context, this means that technology and work in organizations can be regarded as a fusion because people and technologies only exist in relation to each other. This view contains the idea that technologies do not influence humans, but they entail each other in practices through using the technology on a regular basis. Sociomateriality therefore, helps us to balance "the disproportionate attention given to either the social implications of technology use, or the material aspects of technology design" (Johri, 2011, p.207). Instead, we should regard them together through social interactions of people using the technology. Organizations, considering the adoption of an innovative technology, in this research e-HRM technology, should be aware of the "multiple, emergent, and dynamic sociomaterial configurations that constitute contemporary organizational practice" (Orlikowski \& Scott, 2008, P. 434).

\section{Electronic HRM (e-HRM)}

Throughout the past decades, research has been done on how developments of and changes in technological advancements have transformed HRM (Strohmeier \& Kabst, 2009; Foster, 2011; Banerji, 2013; Barzoki, Mazraeh, \& Maleki, 2013; Vashishth, 2014). Using modern technology, HRM has been made more efficient and effective, bringing about immense changes and opportunities to organizations and shaping the concept and use of e-HRM (Oswal \& Narayanappa, 2014; Banerji, 2013).

E-HRM is commonly understood to be the application of technology, to network and support diverse actors in their shared performing of HRM-activities (Strohmeier, 2007). The implementation of e-HRM does not only include the sharing of HRM-services and technology, it also combines the social and material parts of an organization (Bondarouk, Harms \& Lepak, 2015; Juana-Espinoza \& Luján-Mora, 2010). Organizations use e-HRM to empower 
employees, improve their competences, and make HRM-function more flexible and efficient, leading among others to reduction of administrative work and saving costs (Parry \& Tyson, 2011; Oswal \& Narayanappa, 2014; Deshwal, 2015). Bissola and Imperatori (2014) state that e-HRM plays a relevant role in the employee-organizational relationships and contributes to the role of the HRM-department in modern organizations. E-HRM therefore, can be a powerful driving force towards enhancing organizational effectiveness, as it enacts as a technologicaltool to achieve sustainable management, upgrading HRM-activities and stimulating the implementation-flow of business-strategies and processes (Oswal \& Narayanappa, 2014; Deshwal, 2015). In addition, Srivastava (2010) stresses that the introduction of e-HRM applications should not be considered a stage within HRM-development only, but more like a specific choice made for an approach to HRM. E-HRM incorporates a structural change of working and thinking, which is not only bound to the HRM function and its execution, but influences the whole organization, including the interdependent relationships between employees and technology dimensions.

\section{Sustainable e-HRM Implementation}

Strohmeier and Kabst (2009) suggest that a sustainable implementation process requires the adoption of new routines, which entail changing or unlearning existing routines, while simultaneously initiating and implementing new routines. To reach this goal, "managers must devote great attention, conviction and resources to the implementation process" (Klein \& Knight, 2005, p. 246). In other words, for e-HRM applications to be implemented in a sustainable way requires a consistent (long term) and quality usage of the e-HRM technology by targeted users (Bondarouk \& Brewster, 2016a; Klein \& Sorra, 1996). Guest and Bos-Nehles (2012) have found that different stakeholders use various criteria to assess implementation: 
"those who promote HR, those who enact it and those employees affected by it, may arrive at different judgments about implementation effectiveness" (p. 84).

This interaction also reflects the entanglement of material and social/human aspects of a sustainable implementation process, as expressed by the concept of sociomateriality. In this paper, we explore the process of sustainable e-HRM implementation from a sociomateriality perspective. This perspective offers us the opportunity to understand how HRM practices, intertwined with IT and meaning, enact the implementation of these e-HRM practices into regularly used practices (Ellmer \& Reichel, 2018). Sustainable e-HRM can be understood by applying ICT to support and network relevant actors in their consistent shared performance of HRM directed towards simultaneously and consistently supporting the economic, ecological and social performance of the organization (Ehnert, Parsa, Roper, Wagner \& Muller-Camen, 2015; Bondarouk \& Brewster, 2016a). Related to e-HRM, implementation is the critical gateway between the adoption and its routine (sustainable) use of e-HRM. Sustainable e-HRM implementation is therefore achieved when technology and human interaction harmonize, i.e. when employees are happy to use, have learned the essential skills to master, and fully understand the innovative technology (Bondarouk \& Brewster, 2016a).

This social and material interaction can be distinguished on all implementation levels, e.g. the individual-level (adoption of e-HRM by individuals), the organizational-level (adoption of e-HRM by organizational units) and the assumed interaction-effects between both levels (Jeyaraj, Rottman, \& Lacity, 2006). These different implementation levels must contribute and work together to make the utilization of e-HRM successful.

\section{E-HRM Stakeholder Interaction}

The conceptual model has been derived from the research question and the literature that has been reviewed. It demonstrates how the interaction between e-HRM stakeholders (stakeholders 
from HRM, technology and the organization) and their perceptions and needs relate to achieving sustainable e-HRM. As the social and material dimension of an organization are inherently inseparable, interactions between e-HRM stakeholders are bound up in this concept. None of the stakeholders can act without affecting other stakeholders. These relationships can be seen in Figure 1.

\section{IMPLEMENTATION PROCESS}

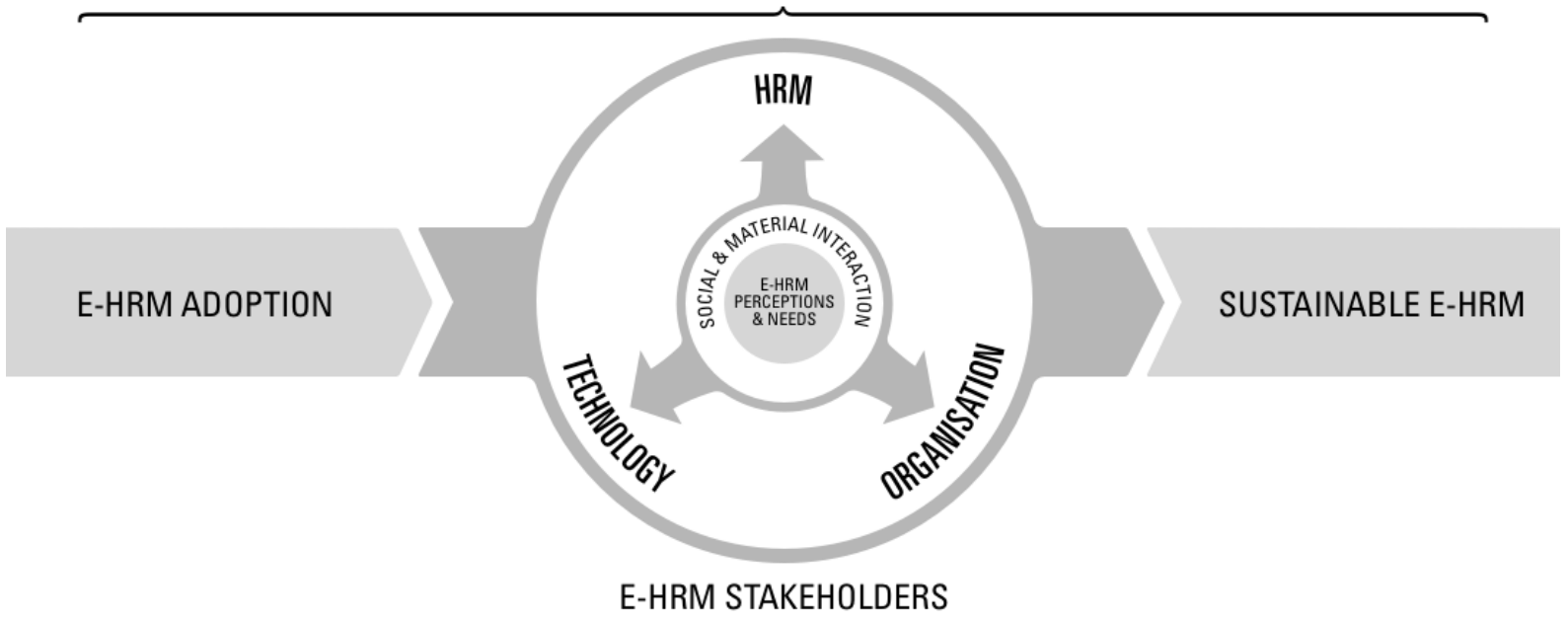

Figure 1 Conceptual model: E-HRM stakeholders' interaction and perception and needs related to sustainable e-HRM implementation

Understanding the interaction between e-HRM stakeholders and their perceptions and needs about e-HRM is believed to be of vital importance within the sustainable e-HRM implementation process. 


\section{METHODOLOGY}

Given the explorative nature of this empirical research - exploring and understanding HRM, technology and organizational stakeholders' perceptions, needs and their interaction, related to achieving sustainable e-HRM implementation - a qualitative research method has been used.

\section{A Single Case Study Design}

The observations were done within an exploratory single case study research design, which was chosen to develop an in-depth analysis of what e-HRM stakeholders' perceptions and needs are, when implementing e-HRM practices.

The relationship between HRM, technology and organizational (e-HRM) stakeholders has still been studied very little in practice. Even more intriguing is the question on how these e-HRM stakeholders' perceptions and needs influence sustainable e-HRM implementation. Because these interdependent relationships have been explored so little, the situation required a more in-depth approach. For this reason, generating new data within a single case study design appeared to be appropriate, as the circumstances demanded more thorough questioning of the selected respondents.

The goal of this research is to contribute to theory building, based on newly gained indepth knowledge, by studying what is needed to achieve sustainable e-HRM implementation, from a e-HRM stakeholders' point of view. A case study approach supports that goal, by providing more detailed information, and offering 'better stories' (interviews) which are helpful in describing the studied phenomena (Dyer \& Wilkins, 1991). 


\section{Case Company Selection}

We selected our case company, based on whether e-HRM adoption had taken place and/or whether the company was still involved in the implementation process. E-HRM implementation is often initiated by companies to increase their competitive advantage. However, this does not always result in sustainable e-HRM implementation. Since various e-HRM stakeholders are involved in a sustainable e-HRM implementation process, we think it is of key importance to understand their perceptions and needs, to help understand potential causes for discrepancies between expectations and final results and help deal with these discrepancies.

\section{Case Company Description}

The case company selected within this research study is a Dutch service organization (approx. 10.000 employees), based in the Netherlands. The company recently introduced an e-HRM application - a personnel-management-application, embedded in iPad technologies - to be used by line-managers' to perform/support different work tasks and processes. According to management, discrepancies between expectations and final results were observed. Causes and circumstances could not be pointed out, since no time and energy had been invested in finding out. This context made the company an ideal candidate, to be selected for this case-study.

The case company introduced twelve technological applications (HRM and non-HRM) in the period between 2012 and 2016. Soon it became clear that a number of line managers found it hard to use e-HRM applications for their daily work processes. Consequently, it was decided to search for causes and give advice for solutions. HRM, technology and organizational stakeholders' questioned on their perceptions, needs and interaction, related to a sustainable implementation process of e-HRM practices. Based upon data collected by the company, specific e-HRM apps were chosen and compared according to their implementation process. 


\section{Sample Selection and Characteristics}

The sample size was based on the total number of potential interviewees. In our case 14 key eHRM stakeholders were drawn, non-randomly and based on criterion sampling, selecting participants who would match the criteria of this study (Rudestam \& Newton, 2015).

The purpose was to explore and understand HRM, technology and organizational stakeholders' and their perceptions, needs and interaction related to the sustainable e-HRM implementation process. To gain a wide range of data, key e-HRM stakeholders were chosen from different organizational layers and units. To select these stakeholders for our study, we used the following selection criteria: employed by the organization; direct interaction with eHRM application during working hours; and interaction with other organizational layers involved in the e-HRM implementation process (HRM, technology and organization).

The selected case company has spread its operational activities over separate regions and units. The company's unit- and line-managers operate in these regional units. During preparatory meetings with the Human Resource (HR) director and the information manager we added a number of criteria based on the case context for selecting e-HRM stakeholders. We selected the following e-HRM stakeholders: the coordinator-region-administrator (CRA), stakeholders from administrational unit, unit managers and line managers. We further selected three different units located in the Eastern part of the Netherlands, which were situated next to each other.

Table 1: Selected key e-HRM stakeholders based on three pillars

\begin{tabular}{|l|l|l|l|}
\hline Pillar & $\begin{array}{l}\text { Number } \\
\text { of } \\
\text { interviews }\end{array}$ & Function & Description of responsibilities \\
\hline \multirow{3}{*}{$\begin{array}{l}\text { HRM } \\
\text { stakeholders }\end{array}$} & 1 & HR director & $\begin{array}{l}\text { Developing rules and regulations and setting } \\
\text { goals prior to the introduction of the e-HRM } \\
\text { application. }\end{array}$ \\
\cline { 2 - 4 } & 1 & Administration & $\begin{array}{l}\text { Responsible for certain tasks prior the e- } \\
\text { HRM app introduction. The work load }\end{array}$ \\
\hline
\end{tabular}




\begin{tabular}{|c|c|c|c|}
\hline & & & $\begin{array}{l}\text { shifted from administration to line managers } \\
\text { because of the e-HRM applications. }\end{array}$ \\
\hline \multirow[b]{2}{*}{$\begin{array}{l}\text { Organization } \\
\text { stakeholders }\end{array}$} & 3 & Unit manager & $\begin{array}{l}\text { Authorizing party to decisions made } \\
\text { by/requests of the line manager. }\end{array}$ \\
\hline & 6 & Line manager & $\begin{array}{l}\text { Direct interaction with the e-HRM } \\
\text { application. }\end{array}$ \\
\hline \multirow{2}{*}{$\begin{array}{l}\text { Technology } \\
\text { stakeholders }\end{array}$} & 1 & $\begin{array}{l}\text { Information } \\
\text { manager }\end{array}$ & $\begin{array}{l}\text { Directly involved with the technical } \\
\text { development of the e-HRM application } \\
\text { apps. }\end{array}$ \\
\hline & 2 & $\begin{array}{l}\text { Coordinator } \\
\text { regional } \\
\text { administration }\end{array}$ & $\begin{array}{l}\text { Point of contact for line managers } \\
\text { concerning questions about the e-HRM } \\
\text { application usage. }\end{array}$ \\
\hline Total & 14 & & \\
\hline
\end{tabular}

\section{Measurement Construction}

Case study designs involve collecting qualitative data from various sources, to explore one or more organizations or parts of organizations and the characteristics of these contexts (Baker, 2010). This approach facilitates the exploration of a phenomenon within its context, using a variety of data sources, ensuring that the issue is not only explored through one, but multiple lenses, allowing the phenomenon to be revealed and understood (Baxter \& Jack, 2008).

The method of measurement is based on multiple sources, including semi-structured indepth interviews as well as the collection and analysis of documents, texts and archival records. Semi-structured interviews were chosen because of their flexibility to respond to the direction in which interviewees takes the interview, leaving room to adjust the emphasis of the research as a result of significant issues that might emerge (Bryman \& Bell, 2011). This gave us the opportunity to explore or describe the phenomenon in context using a variety of data sources (Baxter \& Jack, 2008).

\section{Data Collection Procedure}

The interview data was collected with the help of a semi-structured interview guide, which was based on studied e-HRM implementation literature and by analyzing relevant documents which 
were provided by the company. The interviewees were contacted individually in order to make an appointment for the interview. The length of the individual interviews could not be determined at the start, as it depended on the available time each of the interviewees could offer. However, most interviews were about 40 to 70 minutes long.

\section{Data Analysis}

All the interviews were recorded digitally and transcribed afterwards. The collected data was transcribed, coded and analyzed with ATLAS.ti. Different types of coding used were; open, axial and selective coding. The coding frame was based on provided guidelines for the classification and organization of data, in particular through the creation and maintenance of 'concept cards' (Bryman \& Bell, 2011), which were derived from the research question and interview guide used. These could also be adjusted during the coding process as new relevant issues might emerge. 


\section{RESULTS}

\section{Stakeholders' Perceptions of e-HRM}

In order to understand stakeholders' views and needs to achieve sustainable e-HRM implementation, we ought to understand what they believe e-HRM actually entails. We noticed that depending on their hierarchical position in the organization and field of responsibility, more or less detailed information could be given on the subject. The higher the function, the more detailed information was passed on to us on what e-HRM stands for. Stakeholders from the technology department naturally showed more detailed understanding of what e-HRM entails. Line managers, i.e. targeted users, who are supposed to use e-HRM in their daily routine, found it harder to describe e-HRM.

\section{The Implementation of e-HRM}

The adoption of e-HRM and the other iOS applications started in 2012 and was part of the company's reorganization plan called " $12 / 20$ ". Among other organizational goals, work processes had to be made more efficient and flexible, and overhead costs had to be cut, by placing responsibilities from higher to lower layers and functions within the organization.

\section{Sociomaterial e-HRM Implementation Process}

The social and material dimensions of the e-HRM implementation were indeed highly related as indicated by the sociomateriality perspective. This was evident because e-HRM work processes were highly dependent on technology. They were dependent on external sources such as Wi-Fi or a $3 \mathrm{G} / 4 \mathrm{G}$ Internet connection. If technology failed, work processes did not function. Some of the e-HRM stakeholders (the information manager, unit managers and line managers) repeatedly brought up this topic. How strongly the material and social part were related became 
clear through the dependence of the social dimension on the material dimension. The organization seemed to do everything possible to guarantee consistent internet connections. In case of a failed connection, there were, however, no backup solutions. Suggestions were made to use applications offline and to synchronize changed and/or added information as soon as the user came online again.

E-HRM was an inseparable part of the technology in this case because different work processes used different iOS applications. During our research we noticed that line managers often found it difficult to clearly separate problems related to specific e-HRM applications. The interaction between users of e-HRM and other iOS applications was intensive, making it difficult for targeted users not to mix up different applications.

\section{Social Adaptations in the e-HRM Implementation Process}

The development and introduction of e-HRM and other iOS applications involved intensive interaction between various e-HRM stakeholders and specialists, such as HRM and technology (ICT) specialist, operation managers, unit and line managers. Some line managers felt not well enough informed about and prepared for the development and adoption of the very first e-HRM application. A number of them felt that they had been left out and that development and introduction had not been thought through well. Neither the development nor the implementation process was ever discussed with them. Line managers felt that there was insufficient basic information and the involvement of targeted users was kept to a minimum, resulting in a number of discrepancies between line managers' expectations and results. In the years following, however, line managers' involvement was improved.

"In the beginning we made the mistake by not listening enough to our targeted users" (Information manager) 
To compensate for not involving line managers in the development of the e-HRM applications, the organization recently introduced a communication app that should help all line managers to voice their ideas, concerns or suggestions. This is introduced to involve the practice in the implementation of e-HRM applications because the organization believes that it will help to increase the commitment of line managers towards the technical systems.

Line managers also pointed out that they simply needed more time to get used to the new concept of working and the new responsibilities that came with it. According to line managers, the introduction of the iPad, e-HRM and other applications happened too fast. Suggestions were made by unit managers, who pointed out that the implementation of e-HRM and various other kinds of iOS applications should be done in phases. This way targeted users and other stakeholders can take time to evaluate the systems introduced and improve mistakes. Work processes should also be fully integrated into the system.

“It could have been done in more separate steps. '12/20' indicates that innovation will take place from 2012 until 2020. However, everyone felt that it was more like '12/14'. As if the complete reorganization had to take place within two years, instead of eight, the number of years they had initially committed themselves to." (Line manager 6)

"Especially at the start, for many line mangers e-HRM was still a quite abstract concept. We ought to have involved them more... Thus, generally, I think that we put too little effort to commit our line managers" (HR Director)

During the adoption of e-HRM, line managers had difficulties getting used to iPads, the eHRM and other applications. Mixed feelings were expressed, such as having had needs for 
regular evaluations and a more thorough instruction on how to use iPad, the e-HRM and other applications.

"There are opinions saying that employees might not have been trained well enough and that too much of the training responsibility had been given to the CRA to coach/train targeted users. Concluding, too little effort was made to win over the target users (line managers).” (HR Director)

To help line managers getting used to the iPad and learning to work with it, the organization allowed and recommended that the iPad could be used to play games. The idea was that line managers should use the iPad privately before using it for work processes. In such a way, the usage of an iPad would become normal.

"Well, on the other hand with the introduction of the iPads it was clearly said that it is your iPad, put games on it, play with it. Thus, not to use it only for business purposes, no, learn to deal with it. And learning to deal with an iPad is indeed playing games, face time, I don't know what you need to install to use it...Facebook, I don't know, and that was meant ... use it." (Information manager)

Line managers had mixed reactions about the first introduction of the e-HRM applications and they felt a lack of training. Some line managers expressed having had difficulties. They did not know how to use the iPad and would therefore have appreciated a more guided introduction. Some line managers hinted that the time spent to explain things to them was far too little and they felt intimidated to ask for help. One line manager told us that when she started working, all the applications were explained to her in one single day and in 
about 4 hours, without any breaks in-between. Afterwards she felt dazzled by the new information given to her, because it was too much in a short time. The organization offered training courses and modules to teach line managers to use the applications. However, these consisted of various chapters and that following all chapters took time. The main problem was, however, that line managers already needed to use the iPads while still following the training courses. Especially newly hired line managers cannot work without the iPad and thus need to use the iPad while at the same time following the course. However, the issues learned in a later chapter are often already necessary today and thus line managers made many mistakes in the usage of the applications which needed to be fixed later on.

Concerns were also raised about different levels of knowledge/skills of line managers during training sessions. Not all could follow the speed of training, but they did not express this deficit during training lessons.

\footnotetext{
"Yes, some people weren't used to working with a computer. They knew how to turn it on, how to send an email and that the email eventually would arrive somewhere. But it was a shock for some people who had never seen an iPad, never used a touch-screen and no idea how to use an application." (Line manager 6)
}

As a reaction to these perceived difficulties, line managers started to help each other. They exchanged their understandings of the technology and their way of using the applications. These unplanned and unorganized initiatives of line managers was a reaction to their perceived issues with the use of the iPads or the usage of the applications. These human interactions of key users of the e-HRM practices and applications was a way for line managers to learn from each other about how to apply the technology. 
"If a whole group of people doesn't know the iPad and its applications, then you should pay more attention to guide them through the implementation process! You cannot hand over and say 'Have fun!' [..] If you don't know something and you are afraid to use it, you will not get near the thing! But many targeted users couldn't get around it, because within two months they had to use the iPad and its applications. And that is where mistakes were made [..] Targeted users exchanged work responsibilities with each other. They had known and worked with each other for years, so in a situation like this they helped each other out." (Unit manager 2)

The "social" issues in the implementation process resulted in a couple of initiatives targeted at the role of line managers as users of the technology. Project groups between the CRA, the information manager, unit managers and line managers were set up to discuss the development and adoption process of e-HRM applications. The management team started to understand that line managers ought to have been involved in the process of e-HRM adoption from an early stage on. Thus, now they felt that feedback from line managers (their perceptions and needs) was essential for the organization to achieve sustainable e-HRM implementation.

As a reaction to the unpreparedness and usage issues of line managers with the e-HRM applications, the organization developed new training sessions and support sessions targeted to the line managers. Three years after the adoption of the e-HRM system and usage of apps, they started with organizing so-called "line manager days", an initiative to improve the communication between line managers and the management team. Line managers and members of the management team discuss issues that are regarded as important and line managers are invited to provide the management team with feedback to their plans, initiatives and processes. Next to that, they also initiated "sounding board groups" in which they invited line managers 
to share their ideas of where the organization should head to and to gain their feedback on new initiatives.

"You could seek them more out, you could invite them more to show them what you are doing somewhere else [...] well, these sorts of instruments. This we could set in more intensively than we used to do that." (HR Director)

Another initiative the organization took to solve the social problems of getting used to the material usage was to put more pressure on the users of the e-HRM applications. Some of the applications, especially the HRM applications, needed to be used, there was no alternative. By forcing target users to use the applications, the organization aimed to increase the usage of the technology.

"Yes, but the advantage of the HRM applications is that these are things you need to use. Full stop. [...] Thus, we were much more imposing an obligation saying you just need to do this." (Information manager)

\section{Material Adaptations in the e-HRM Implementation Process}

E-HRM stakeholders' perceptions differed on how well e-HRM systems operated. Issues that had initially led to resistance of usage and/or irritations, as pointed out by unit and line managers, were mostly of a technical nature. Among them were: a poor internet connection/coverage (in rural areas), a weak network provider, the system's sluggishness when used at peak times, the systems did not synchronize fast enough and the incompatibility of different systems used. For example, not being able to synchronize between different operational systems such as iOS, Windows or Google or having to open 4-5 different 
operational systems in order to see all the relevant information needed often led to reluctance to use the e-HRM applications and apps on a regular basis. The seeming inefficiency of some of the ICT systems used made it difficult for targeted users to operate in an efficient way, leading to increased resistance.

The organization created a new function to manage all applications. This is the information manager. This manager is responsible for the maintenance of existing e-HRM applications and development and implementation of new e-HRM applications. The information manager needs to change the applications when needed.

"Everything related to HR and ICT, I am responsible for, well for the maintenance so to say. Thus, improving things, of course there are always change requests, or issues such as you know this actually does not run well, that we want to have adapted." (Information manager)

E-HRM applications needed to be adapted because they were incomplete or missed specific usage areas. Through using the e-HRM applications, target users experienced usage issues of faults in the system, which could be changed. For example, the selection of new employees happened in only 90 percent of all cases via the app because the app was not programmed for employees that were taken over from competitors or through fusions. To guarantee 100 percent usage, the application needed to be adjusted and completed.

"You see that of the newly selected employees, $90 \%$ goes through the app and 10\% through SAP. When actually 100\% should go through the app, but that is not possible because for example the app cannot do take-overs...people that came in through takeovers. [...] These sorts of things all need to be adapted." (HR Director) 
"In December 2012 we went live. If you take the employment app from then and put it next to the one of today, anyway a lot has changed, adapted and done." (Information manager)

To tackle any technological support for targeted users, the organization offers support through the administration, the CRA or helpdesk. The CRA is responsible for training line managers how to use e-HRM applications and was introduced to help line managers solve technological issues related to the e-HRM applications.

Since line managers often did not find CRA support and did not perceive their services as useful, some unit managers have created their own solution to speed up the process for small technical issues. They assigned one of their line managers to support and help other line managers within their unit. This example shows that target users did not only help each other to optimize the social dimensions of the e-HRM implementation, but also the material dimension. Through this human-human interaction with the technology line managers could help each other to deal with the technology issues the system had.

"It's inefficient to call CRA for each small problem, first you have to try to solve it on your own. Then you can ask a colleague and if that still doesn't work, you call CRA." (Line manager 1) 


\section{DISCUSSION AND CONCLUSION}

Within the present research our focus lay on answering the central research question which was: In what way do social and material dimensions interact in the process of implementing e-HRM applications sustainably? To understand the social and material interaction between e-HRM stakeholders and how this interaction is related to achieving sustainable e-HRM implementation, we performed an exploratory research. Our results show that the sustainable implementation of e-HRM applications is a socio-material process in which social and material dimensions interact during the implementation.

A sustainable implementation of e-HRM applications can be regarded as a sociomaterial process, because the to implement these applications sustainably the social and material dimensions need to be inherently connected. In this case, this was evident from the dependence on the technology. Usage of the e-HRM applications was impossible without strong internet connections and networks. Further, the applications could not be used well when the technology was poor, as in situations of technical problems, faults in the system or usage unfriendliness. On the other hand, the iPads or e-HRM applications were not used or not used well when users perceived fear of technology, perceived that they could not influence the development and implementation of the technology and were not trained to use it.

To implement the e-HRM applications sustainably, the organization needed to make a few adaptations on the social and the material side. Social adaptations focused on the usage of the e-HRM applications and on the target users. To involve them more in the development and implementation of the applications and give them voice to raise concerns, offer suggestions and ask questions, the organization developed a communication app and invited line managers to participate in discussions with the management board in line manager days and sounding board groups. Additionally, the organization organized project groups to better support the line in 
usage questions. Material adaptations focused on a professional organization around maintenance and further developments of applications and solving technical issues.

Based on the suggestions of Orlikowski (2009) that technology needs to be used and that by using the technology, the technology develops further during the implementation process. The case organizations forced users to use the new technology by putting more pressure on usage. They realized that the e-HRM applications will be sustainably implemented through usage. Users realize faults and issues with the technology, which need to be adapted, and they also realize their own shortcomings, such as training or preparedness for technology usage. This process of developing the social and material dimensions will lead to more usage and thus more sustainable implementation of the e-HRM applications.

To cope with social or material issues in the implementation process, users started to interact with each other and the material (Orlikowski, 2009; Orlikowski \& Scott, 2008). Different stakeholders in the implementations process interacted to use the e-HRM applications, such as line managers with CRA managers, the information manager and unit managers. These interactions were between the social side (e.g. users) and the material side (e.g. software developers, ICT support, information manager), but also among social actors (e.g. various line managers). In case of user or usage issues, line managers would either ask "material" stakeholders or "social" stakeholders for support. Thus they would contact the ICT support or their unit manager and other line managers for support. Thus we say various forms of interactions, such as social-material interactions, material-material interactions and socialsocial interactions between various e-HRM stakeholders. For example, we say human-human interactions between users of the technology, i.e. various line managers at various departments of hierarchies helped each other to cope with the technology. Another example is that line managers would develop their own solutions for technical issues, with or without technical support. Orlikowski (2009) suggested these forms of support between different actors in the 
implementation process. While she focused mainly on interactions between humans and nonhumans, we saw many examples of human-human interactions on the implementation of the eHRM applications. Thus our findings show that the perceptions and needs about e-HRM, and the interaction between e-HRM stakeholders play a very important role in achieving sustainable e-HRM implementation.

\section{Limitations and Future Research}

This research aims to produce a generalizable theory about how to achieve sustainable e-HRM within the context of sociomateriality. Understanding the interaction between e-HRM stakeholders and how their perceptions and needs about e-HRM influence the achievement of sustainable e-HRM implementation.

We started this research four years after e-HRM adoption. It would have been better, however, if this research would have either been conducted immediately after the introduction of iPads and e-HRM applications, or over a certain period of time to see how the perceptions and needs about e-HRM of different e-HRM stakeholders have changed over time. We did consider this limitation during our research by asking stakeholders how they felt at the beginning or prior to the e-HRM adoption and how their perceptions and needs have changed over the years.

Reliability within qualitative research is concerned with the degree to which the research results obtained are interrupted by assumptions or errors. In order to prevent bias, we have used data-triangulation, combining semi-structured in-depth interviews, voice records, literature review and various other sources of data (Bryman \& Bell, 2011). Reliability of the in-depth interviews however, can be affected by the researcher because in qualitative research the researcher can exert influence on the respondent and vice versa. 
This research aims to explore how sustainable e-HRM implementation can be achieved, related to the concept of sociomateriality. The ideas expressed by the concept of sociomateriality are still novel to organizational research. Our model may present a starting point to understanding the interaction between the social and material dimensions of an organization related to achieving sustainable e-HRM implementation. We could show in what ways the social and material dimensions interacted and in what way the organization offered initiatives for social and material adaptions during the implementation. We suggest that more e-HRM researchers accept the challenge of exploring social-material dimensions of e-HRM and the interaction between social and material dimensions within the organizational context of e-HRM implementation. 
Baker, G. R. (2010). The contribution of case study research to knowledge of how to improve quality of care. BMJ Quality and Safety , 20 (Suppl 1), i30-i35, DOI:10.1136/bmjqs.2010.046490.

Banerji, S. C. (2013). A Study of Issues \& Challenges of Implementation of Information Technology in HRM. Global Journal of Management and Business Studies , 3 (4), 435-440.

Barzoki, D. A., Mazraeh, S., \& Maleki, S. (2013). Feasibility of Implementing Electronic Human Resource Management (E-HRM) Case Study: Isfahan Municipality. 7th International Conference on e-Commerce in Developing Countries with focus on e-Security (pp. 1-16). Kish Island: IEEE.

Baxter, P., \& Jack, S. (2008). Qualitative Case Study Methodology: Study Design and Implementation for Novice Researchers. The Qualitative Report, 13 (4), 544-559.

Bissola, R., \& Imperatori, B. (2014). The unexpected side of relational e-HRM Developing trust in the HR department. Employee Relations , 36 (4), 376-397, DOI: 10.1108/ER-07-20130078.

Bondarouk, T., \& Brewster, C. (2016a). Conceptualising the future of HRM and technology research. The International Journal of Human Resource Management , 27 (21), 2652-2671, DOI: $10.1080 / 09585192.2016 .1232296$.

Bondarouk, T., Harms, R., \& Lepak, D. (2015). Does e-HRM lead to better HRM service? The International Journal of Human Resource Management , 26, 1-31, DOI:10.1080/09585192.2015.1118139.

Bryman, A., \& Bell, E. (2011). Business Research Methods (Vol. 3). New York: Oxford University Press Inc.

Cohen, E., Taylor, S., \& Muller-Camen, M. (2012). HRM's Role in Corporate Social and Environmental Sustainability. SHRM Foundation. 
Dyer, W. G., \& Wilkins, A. L. (1991). Better stories, not better constructs, to generate better theory - a rejoinder to Eisenhardt. Academic Management Review , 16 (3), 613-619, DOI: 10.5465/AMR.1991.4279492.

Ehnert, I., Parsa, S., Roper, I., Wagner, M., \& Muller-Camen, M. (2015). Reporting on sustainability and HRM: a comparative study of sustainability reporting practices by the world's largest companies. The International Journal of Human Resource Management, 1-21, DOI: 10.1080/09585192.2015.1024157.

Foster, S. (2011). Making Sense of e-HRM: Transformation, Technology and Power Relations. In M. Khosrow-Pour (Ed.), Enterprise Information Systems: Concepts, Methodologies, Tools and Applications (Vol. 3, pp. 2178; DOI: 10.4018/978-1-61692-852-0). Information Resources Management Association.

Guest, D., \& Bos-Nehles, A. (2012). HRM and performance: the role of effective implementation. In D. Guest, J. Paauwe, \& P. Wright, HRM and performance: Achievements and challenges (pp. 79 - 96). Wiley-Blackwell, Chichester.

Jeyaraj, A., Rottman, J. W., \& Lacity, M. C. (2006). A review of the predictors, linkages and biases in IT innovation adoption research. Journal of Information Technology , 21 (1), 1-23, DOI: 10.1057/palgrave.jit.2000056 .

Johri, A. (2011). The socio-materiality of learning practices and implications for the field of learning technology. Association for Learning Technology, 19 (3), 207-217.

Jolly, D. R. (2004). Editorial: human issues in implementing information and communication technologies: perspectives from different countries. Int. J. Human Resources Development and Management , 4 (4), 335-344.

Juana-Espinosa, S. d., \& Luján-Mora, S. (2010). Putting e-HR into practice: the case of the University of Alicante. In S. Strohmeier, \& A. Diederichsen (Ed.), Proceedings of the 3rd 
European Academic Workshop on Electronic Human Resource Management. 570, pp. 342-359.

Bamberg, Germany: CEUR Workshop Proceedings (CEUR-WS.org).

King, N. (2004). Using templates in the thematic analysis of text. In \&. G. C. Cassel, Essential Guide to Qualitatieve Methods in Organizational Research (pp. pp. 256-270). London: Sage.

Klein, K. J., \& Knight, A. P. (2005). Innovation Implementation - Overcoming the Challenge. Current Directions in Psychological Science, 14 (5), 243-246, DOI: 10.1111/j.09637214.2005.00373.x.

Klein, K. J., \& Sorra, J. S. (1996). The Challenge of Innovation Implementation. The Academy of Management Review, , 21 (4), pp. 1055-1080.

Leonardi, P. M. (2013). Theoretical foundations for the study of sociomateriality . Information and Organization , 23, 59-76.

Orlikowski, W. J., \& Scott, S. V. (2008). Sociomateriality: Challenging the Separation of Technology, Work and Organization. The Academy of Management Annals , 2 (1), 433-474.

Oswal, N., \& Narayanappa, P. G. (2014). Evolution of HRM to E-HRM towards Organizational Effectiveness and Sustainability. International Journal of Recent Development in Engineering and Technology, 2 (4), 7-14.

Parry, E., \& Strohmeier, S. (2014). HRM in the digital age - digital changes and challenges of the HR profession. Employee Relations , 36 (4), DOI: 10.1108/ER-03-2014-0032.

Parry, E., \& Tyson, S. (2011). Desired goals and actual outcomes of e-HRM. Human Resource Management Journal , 21 (3), 335 - 354.

Rudestam, K. E., \& Newton, R. R. (2015). The Method Chapter. SAGE Publications, Inc.

Scott, S. V., \& Orlikowski, W. J. (2008). Sociomateriality: Challenging the separation of Technology, Work and Organization. The Academy of Management Annals , 2 (1), 433-474.

Srivastava, S. K. (2010). Shaping Organization with e-HRM. International Journal of Innovation, Management and Technology , 1 (1), 47-50. 
Strohmeier, S. (2012). Assembling a Big Mosaic - A Review of Recent Books on Electronic Human Resource Management (e-HRM). Zeitschrift für Personalforschung , 26 (3), 282-294, DOI: 10.1688/1862-0000_ZfP_2012_03_Strohmeier.

Strohmeier, S. (2007). Research in E- HRM: Review and implication. Human Resurce Management Review , 17 (1), 19-37, DOI: 10.1016/j.hrmr.2006.11.002.

Strohmeier, S., \& Kabst, R. (2009). Organizational adoption of e-HRM in Europe An empirical exploration of major adoption factors. Journal of Managerial Psychology , 24 (6), 482-501, DOI: 10.1108/02683940910974099.

Vashishth, M. (2014). Role of IT in HRM: Opportunities and Challenges. Paripex, Indian Journal Of Research, 03 (04), 159-160. 